DOI: https://doi.org/10.24127/ajpm.v10i1.3163

\title{
IDENTIFIKASI HOMBO BATU SEBAGAI MEDIA PEMBELAJARAN DITINJAU SECARA MATEMATIS
}

\author{
Rohpinus Sarumaha ${ }^{1 *}$, Efrata Gee ${ }^{2}$ \\ $1^{*, 2}$ Pendidikan Matematika, STKIP Nias Selatan, Indonesia \\ *Corresponding author \\ Email: roisarma@gmail.com $^{1 *}$ \\ efratagee2709@gmail.com $^{2)}$
}

Received 15 October 2020; Received in revised form 12 March 2021; Accepted 31 March 2021

\begin{abstract}
Abstrak
Kebudayaan merupakan wujud dari norma, nilai dan adat istiadat berperan penting pada dunia pendidikan secara khusus dalam pembelajaran matematika. Nias Selatan yang kaya akan budaya dapat menjadi referensi bagi guru matematika untuk menciptakan media pembelajaran. Kebudayaan yang sangat menarik untuk dijadikan sebagai media pembelajaran matematika yaitu budaya "hombo batu". Penelitian ini bertujuan untuk mengidentifikasi hombo batu dan mendeskripsikan konsep matematika yang terdapat di dalamnya sehingga dapat digunakan sebagai media pembalajaran matematika. Pendekatan Penelitian ini adalah penelitian kualitatif dengan jenis penelitian etnografi. Fokus penelitian ini adalah budaya hombo batu di Kabupaten Nias Selatan. Teknik pengumpulan data yang digunakan adalah observasi, wawancara dan dokumentasi. Berdasarkan hasil penelitian dan pembahasan, hombo batu memiliki 4 konsep-konsep matematika secara umum yaitu konsep limas persegi panjang terpancung masing-masing titik sudut, rusuk, sisi atau bidang, diagonal sisi, diagonal ruang, bidang diagonal, persegi panjang, trapesium, jaring-jaring, luas permukaan dan volume; konsep kesebangunan masing-masing sebangun dan kongruen; konsep geometri transformasi masing-masing refleksi dan dilatasi; serta konsep pola bilangan, sehingga budaya hombo batu dapat dijadikan sebagai media pembelajaran matematika.
\end{abstract}

Kata Kunci: Hombo batu; konsep matematika; media pembelajaran matematika.

\begin{abstract}
Culture is the realization of norms, values, and customs that takes important role in education field particularly in the learning of mathematics. South Nias with rich cultures can become reference for mathematics teacher to create media of learning. The very interesting culture that can be used as the media of learning of mathematics is culture which named "hombo batu". This research aims at identifying hombo batu and describing the mathematics concept that found within it so it can be used as the media of learning of mathematics. This research is designed in qualitative research design through ethnography research approach. The focus of this research is culture "hombo batu" in South Nias Regency. The techniques of data collection that used are observation, intervew and documentation. Based on the results of research and discussion, hombo batu has four mathematical concepts in general, they are truncated rectangular pyramid off at each corner points, edges, side or field, diagonal side, diagonal space, rectangle, trapezoid, nets surface area and volume; the similarities are congruent and congruent respectively, the transformation geometry of each reflection and dilatation, and number patterns, so that the hombo batu culture can be used as a medium for learning mathematics.
\end{abstract}

Keywords: Hombo batu; mathematical concepts; media of learning of mathematics.

This is an open access article under the Creative Commons Attribution 4.0 International License

\section{PENDAHULUAN}

Hombo batu salah satu kearifan lokal yang ada di kepulauan Nias secara khusus di wilayah Nias Selatan. Budaya hombo batu sejak dulukala digunakan untuk melatih kekuatan fisik dan ketangkasan (Siregar \& Syamsuddin, 2015) pemuda Nias agar menjadi kuat. Disamping itu budaya hombo batu saat ini sering digunakan pada acara-acara 
adat yang sifatnya sakral dan pada acara penyambutan tamu kehormatan. Selain memiliki nilai-nilai karakter, dilakukan pada kegatan seremonial dan formal, hombo batu juga mengandung konsepkonsep matematika, ini sebagai bukti bahwa budaya meliliki keterkaitan dengan matematika.

Matematika adalah ilmu pengetahuan yang selalu diaplikasikan dan dilakukan ditengah kehidupan bermasyarakat, namun kenyataannya sebagian besar masyarakat tidak menyadari keberadaannya. Keberadaan matematik ini tampak jelas pada kebudayaan masyarakat. Kebudayaan masyarakat bila dilihat berdasarkan sifatnya terbagi atas dua yakni: kebudayaan material dan non material (Mustawhisin et al., 2019). Kebudayaan material lebih bersifat jasmaniah yang dapat dilihat secara fisik atau berwujud nyata sebagai contoh hombo batu di Nias Selatan. Dari bentuk dan ciri-ciri hombo batu jelas bahwa budaya memiliki hubungan dengan matematika (Risdiyanti \& Prahmana, 2018) karena matematika sebagai produk budaya (Puspadewi \& Putra, 2014).

Kearifan lokal dikenal dalam budaya sangat penting untuk dilakukan pengkajian dan diterapkan diberbagai bidang ilmu, salah satunya dalam bidang ilmu matematika. Kajian budaya yang berkaitan dengan matematika dikenal dengan istilah etnomatematika (Ulya \& Rahayu, 2020). Etnomatematika merupakan matematika yang tumbuh dan berkembang dalam kebudayaan masyarakat tertentu (Laurens, 2017). Artinya, melalui kebudayaan matematika dapat dipelajari dan dipahami. Sejalan dengan pernyataan yang menegaskan bahwa praktik budaya memungkinkan tertanamnya konsep-konsep matematika (Fajriyah, 2018). Jelas bahwa melalui budaya, matematika dapat dijebatani sehingga konsep-konsep matematika dapat dipahami siswa dengan baik. Oleh karena itu, Indonesia yang kaya akan budaya, dapat menjadi sumber referensi bagi guru matematika untuk menciptakan media pembelajaran dengan memanfaatkan kearifan lokal.

Pemanfaatan kearifan lokal sebagai media pembelajaran matematika merupakan perwujudan dari pelestarian budaya melalui pendidikan. Dengan demikian penempatan budaya sebagai media pembelajaran adalah tindakan yang baik untuk mendukung pengertian bahwa matematika memiliki peranan penting dalam kehidupan manusia (Siagian, 2016), sekaligus membantu keefektifan proses pembelajaran matematika (Fauzi \& Lu'luilmaknun, 2019). Hal tersebut sepaham dengan yang diungkapkan bahwa pembelajaran matematika melalui ethnomathematics dapat membentuk karakter peserta didik yang memahami budayanya dengan baik dan mengaplikasikannya dalam kehidupan sehari-hari (Supriadi et al., 2016). Oleh karena itu, melalui penggunaan media pembelajaran yang di dalamnya terintegrasi nilai-nilai kearifan lokal (Supriadi et al., 2016) memberikan penguatan bagi siswa untuk menghubungkan matematika dengan kehidupan nyata (Fajriyah, 2018; Herlina \& Hartono, 2015).

Korelasi antara matematika dengan kearifan lokal/ budaya terletak pada konsep-konsep matematik yang terdapat di dalamnya. Ada beberapa penelitian terdahulu terkait dengan budaya berkorelasi dengan matematika sebagai contoh konteks budaya melayu dengan konsep pecahan (Pratama et al., 2017), bangunan Temple di Kyoto Jepang yang berhubungan dengan konsep geometri seperti segitiga dan trapesium, jajargenjang, persegi dan persegi panjang serta balok (Dwidayati, 2019), 
bangunan cagar budaya semarang dengan konsep geometri (Hariyadi \& Muttaqin., 2020), sumur purbakala desa Kaliwadas dengan konsep geometri (Noto et al., 2018), budaya Maluku dengan konsep bilangan, pecahan dan geometri (Laurens, 2017), permainan tradisional Yogyakarta dengan konsep operasi bilangan, bagun datar, kesebangunan, kekongruenan, perbandingan, bilangan ganjil dan relasi, motif batik khas Yogyakarta dengan konsep transformasi geometri (Risdiyanti \& Prahmana, 2018), dan lain sebagainya. Kegiatan mengkorelasikan matematika dengan kearifan lokal/ budaya ini tentu menjadi tugas dari guru mata pelajarannya.

Dari berbagai penelitian terdahulu, budaya hombo batu juga memiliki nilainilai matematika. Budaya hombo batu secara struktur bahasa Nias memiliki dua makna. Pertama, hombo batu memiliki makna suatu kegiatan melompati batu atau loncat batu. Kedua, batu loncat. Penelitian terdahulu menegaskan bahwa hombo batu memiliki nilai-nilai karakter pendidikan. Nilai-nilai karakter positif tersebut seperti kekuatan fisik dan ketangkasan, keberanian dalam mengambil keputusan dan resiko hidup, serta daya juang dan semangat heroik (Siregar \& Syamsuddin, 2015). Selain itu hombo batu dapat digunakan sebagai media pembelajaran pada materi gerak parabola (Gea, 2017). Penelitian tersebut berdasarkan makna hombo batu sebagai kegiatan melompati batu atau loncat batu. Sedangkan dalam penelitian ini, membahas makna kedua yaitu batu loncat atau batu itu sendiri. Pengkajian hombo batu ini berdasarkan bentuknya yang menyerupai limas terpancung dan unsur-unsurnya serta konsep matematika lain yang terdapat didalamnya.

Berdasakan latar belakang dan hasil penelitian terdahulu terbukti bahwa hombo batu memiliki konsep-konsep matematika, sehingga hombo batu dapat digunakan sebagai media pembelajaran matematika. Penggunaan konteks hombo batu pada pembelajaran matematika adalah solusi baik dalam membantu siswa dalam memahami konsep matematika mulai dari bentuknya yang menarik sampai pada unsur matematika yang terkandung di dalamnya.

\section{METODE PENELITIAN}

Pendekatan penelitian yang digunakan dalam penelitian ini merupakan penelitian kualitatif. Lokasi penelitian ini adalah di Kabupaten Nias Selatan yang memiliki hombo batu, yang berjumlah 7 Kecamatan yaitu Kecamatan Telukdalam, Kecamatan Fanayama, Kecamatan Luahagudre Maniamolo, Kecamatan Maniamolo, Kecamatan Toma, Kecamatan Onolalu, dan Kecamatan Mazino yang terdiri dari 35 desa. Karena bentuk hombo batu pada umumnya sama maka penelitian lebih difokuskan di Desa Bawomataluo yang merupakan desa pariwisata dan banyak dikunjungi oleh wisatawan.

Jenis penelitian yang digunakan pada penelitian ini adalah penelitian etnografi. Penelitian etnografi ini terkait dengan menggambarkan, menganalisis, mengkaji unsur-unsur dan kejadian serta fenomena-fenomena yang terdapat pada suatu budaya tertentu. Objek penelitian ini adalah budaya hombo batu di Nias Selatan dengan tujuan menemukan konsep-konsep matematika yang terdapat pada hombo batu sehingga dapat digunakan sebagai media pembelajaran matematika. Untuk mencapai tujuan tersebut, tahapantahapan penelitan yang dilakukan adalah: tahap pendahuluan, tahap penyusunan instrumen, tahap pelaksanaan penelitian, tahap analisis data, dan tahap penarikan kesimpulan. 
Pada tahap pendahuluan dilakukan dengan cara memahami situasi kebudayaan hombo batu melalui observasi awal. Kegiatan observasi awal ini, dilakukan untuk melihat nilai-nilai matematik yang terdapat pada hombo batu serta meminta izin kepada pengurus desa terkait penelitian ini.

Pada tahap penyusunan instrumen penelitian yang dilakukan adalah menyusun lembar observasi yang merupakan salah satu instrumen untuk melihat bagaimana bentuk hombo batu secara ontology dari sudut pandang matematika diawali dari bentuk, susunan batu, dan unsur-unsur matematika lainnya. Karena observasi yang dilakukan terkait dengan situasi sosial maka objek yang diamati adalah berupa benda-benda yang terdapat di lingkungan masyarakat Nias Selatan berupa hombo batu. Selain observasi penelitian ini juga menggunakan wawancara dan dokumentasi. Wawancara digunakan untuk menggali informasi terkait sejarah hombo batu dan cara berpikir matematik masyarakat dan dokumentasi digunakan untuk mendokumentasikan objek yang diteliti dan proses penelitian untuk mendukung penelitian.

Pada tahap penelitian, yang pertama dilakukan adalah mengobservasi hombo batu berdasarkan panduan observasi, melakukan pendokumentasian hombo batu dari bebagai sisi hombo batu, serta melakukan wawancara secara mendalam kepada pengurus hombo batu dan penatua adat. Tahapan peneltitian ini dilakukan sedemikian rupa sehingga data atau informasi yang diperoleh mampu menjawab rumusan masalah dan tujuan penelitian tercapai.

Tahap analisis data dilakukan dengan cara mengorganisasikan data hasil penelitian sesuai dengan tujuan penelitian yaitu mengidentifikasi dan mendeskripsikan konsep-konsep matematika yang terdapat pada hombo batu dan mendeskripsikan hombo batu sebagai media pembelajaran matematika.

Pada tahap akhir dilakukan penarikan kesimpulan berdasarkan hasil analisis data. Kesimpulan akhir yang diperoleh dikemas sedemikian rupa sehingga diperoleh informasi bahwa hombo batu memiliki konsep-konsep matematika dan dapat digunakan sebagai media pembelajaran matemtika.

\section{HASIL DAN PEMBAHASAN}

Hombo batu merupakan warisan dari leluhur suku Nias khususnya di wilayah Kabupaten Nias Selatan. Meskipun hombo batu ini berada di wilayah Nias Selatan namun hanya beberapa kecamatan tertentu saja yang memang memiliki budaya hombo batu, diantaranya Kecamatan Telukdalam, Kecamatan Fanayama, Kecamatan Luahagudre Maniamolo, Kecamatan Maniamolo, Kecamatan Toma, Kecamatan Onolalu, dan Kecamatan Mazino. Pada awalnya hombo batu dibuat untuk melatih kekuatan fisik dan ketangkasan pemuda Nias dalam menghadapi tantangan terlebih lagi dalam peperangan antar daerah. Saat ini budaya hombo batu digunakan dalam acara-acara adat yang sifatnya sakral dan penyambutan tamu-tamu kehormatan, serta hombo batu dijikan sebagi kontes atau perlombaan.

Berdasarkan hasil penelitian diperoleh bahwa bentuk hombo batu, maka ada beberapa konsep matematika yang terkandung di dalamnya. Pada dasarnya hombo batu diberbagai tempat di Nias Selatan memiliki bentuk yang sama yaitu menyerupai limas persegi panjang terpancung. Tampilan sisi depan, sisi belakang, sisi kanan dan sisi kiri hombo batu tampak pada Gambar 1 sampai dengan Gambar 4. 


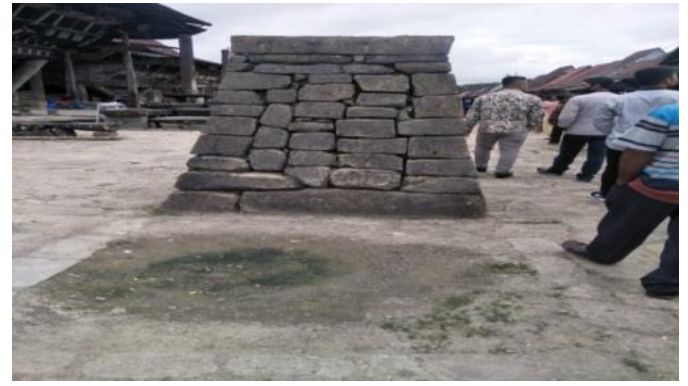

Gambar 1. Tampilan sisi depan hombo batu

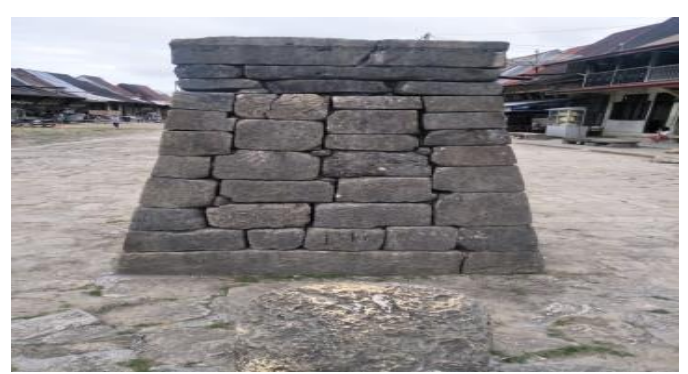

Gambar 2. Tampilan sisi belakang hombo batu

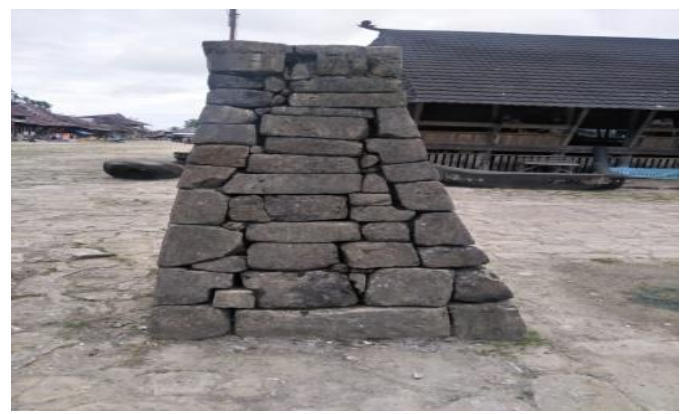

Gambar 3. Tampilan sisi kanan hombo batu

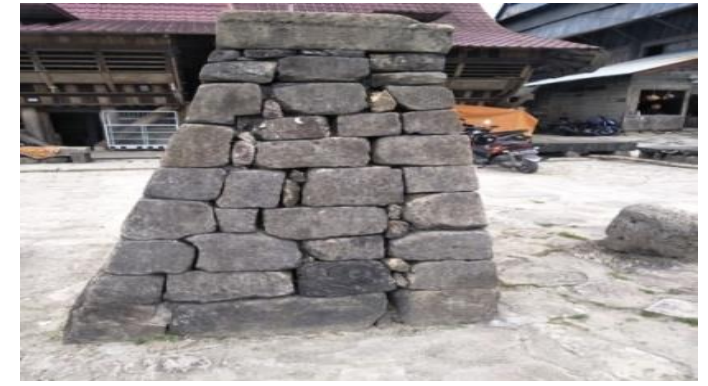

Gambar 4. Tampilan sisi kiri hombo batu

Berdasarkan Gambar 1 sampai dengan Gambar 4, tampak jelas bahwa dari bentuk hombo batu tersebut terdapat beberapa konsep matematika seperti halnya pada limas persegi panjang terpancung diantaranya: konsep titik sudut; rusuk, sisi atau bidang; diagonal sisi; diagonal ruang; bidang diagonal; persegi panjang; trapesium; jaringjaring, luas permukaan dan volume. Selain itu, hombo batu juga memiliki konsep kesebangunan, geometri transformasi seperti refleksi dan dilatasi, serta konsep pola bilangan. Untuk memahami lebih jelas terkait korelasi antara konsep-konsep matematika yang telah disebutkan sebelumnya dengan bangunan hombo batu dapat dilihat pada Gambar 5.
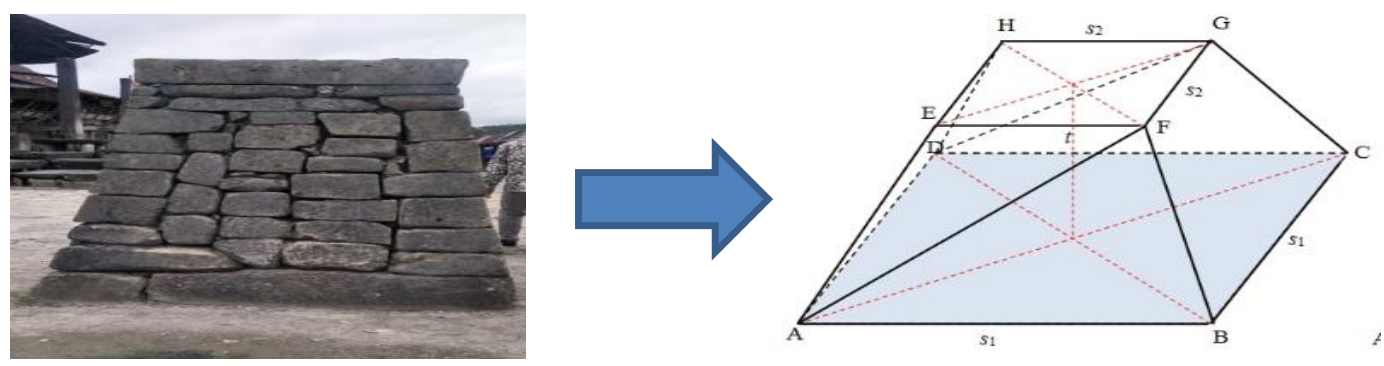

Gambar 5 Hombo batu menyerupai limas persegi panjang terpancung

Penjelasan terkait konsep-konsep matematika dalam hombo batu tersebut adalah sebagai berikut: Titik sudut adalah titik temu antara dua atau lebih ruas garis. Seperti halnya pada bangun ruang pada umumnya hombo batu memiliki 8 (delapan) titik sudut dimana 4 (empat) titik sudut pada bagian alas atau bawah dan 4 (empat) titik sudut pada bagian tutup atau atas seperti tampak pada Gambar 6. 


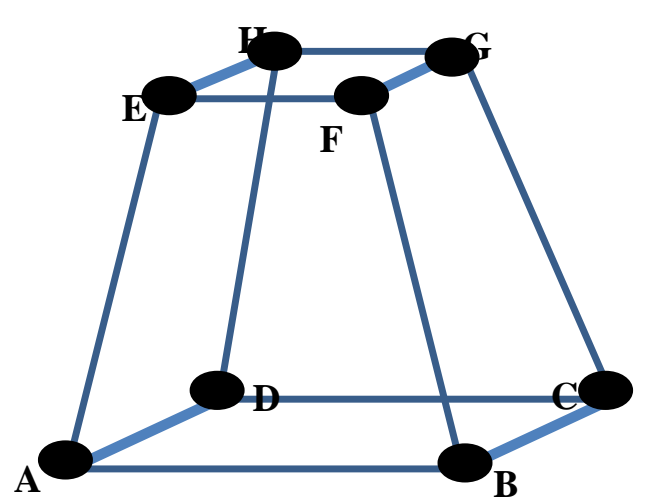

Gambar 6. Tampilan titik hombo batu

Rusuk adalah ruas garis yang terdapat pada bangun ruang. Pada hombo batu terdapat 12 rusuk yaitu rusuk $\mathrm{AB}, \mathrm{AD}, \mathrm{BC}, \mathrm{CD}, \mathrm{AE}, \mathrm{BF}, \mathrm{CG}$, $\mathrm{DH}, \mathrm{EF}, \mathrm{EH}, \mathrm{FG}, \mathrm{GH}$ dengan 4 pasang rusuk yang saling sejajar yaitu $\mathrm{AB} \| \mathrm{EF}$, BC || FG, CD \|| GH, AD || EH.

Sisi atau bidang adalah bangun datar yang memiliki permukaan datar. Pada hombo batu terdapat 6 (enam) sisi masing-masing sisi depan (ABEF), sisi belakang $(\mathrm{CDGH})$, sisi kiri $(\mathrm{ADEH})$, sisi kanan (BCFG), sisi atas (EFGH) dan sisi bawah (ABCD.

Diagonal sisi adalah ruas garis yang menghubungkan dua titik sudut yang berhadapan pada sisi-sisi yang sama pada suatu bangun ruang. Dari bentuk hombo batu tampak bahwa terdapat 12 (dua belas) diagonal sisi masing-masing 2 (dua) diangonal pada sisi atau bidang yang membentuk hombo batu. Diagonal-diagonal tersebut adalah AC, BD, AF, BE, BG, CF, CH, DG, AH, DE, EG, dan.

Diagonal ruang adalah ruas garis yang menghubungkan dua titik sudut yang saling berhadapan di dalam suatu bangun ruang. Pada hombo batu ada 4 (empat) buah diagonal ruang masingmasing AG, BH, DF, dan CE.

Bidang diagonal adalah bidang yang saling menguhubungkan sisi-sisi yang saling berhadapan pada suatu bangun ruang. Pada hombo batu ada 6 (enam) bidang diagonal yang menghubungkan sisi-sisi yang saling berhadapan masing-masing $\mathrm{ABGH}$, CDEF, ACEG, BDFH, BCEH, ADFG.

Persegi panjang sering disebut dengan empat persegi panjang dengan sifat-sifat sisi yang berhadapan memiliki panjang yang sama, setiap sudutnya siku-siku, mempunyai 2 buah diagonal, 2 sumbu simetri, kelilingnya adalah $2(p+l)$ dan luasnya adalah p.l. Pada hombo batu terdapat 2 buah persegi panjang yaitu bagian atas (EFGH) dan bagian bawah (ABCD.

Trapesium adalah bangun datar yang memiliki dua buah sisi sejajar. Pada hombo batu pada umumnya memiliki 4 sisi atau bidang yang berbentuk trapesium yaitu pada bagian sisi depan (ABEF), sisi belakang (CDGH), sisi kanan (BCFG), dan sisi kiri (ADEH). Trapesium pada hombo batu hanya memiliki 2 bentuk yaitu trapesium sama kaki, trapesium sembarang.

Jaring-jaring adalah bentangan dari sisi atau bidang suatu bangun ruang secara utuh pada bidang datar. Konsep jaring-jaring pada hombo batu salah satunya dapat menyerupai bentuk seperti terlihat pada Gambar 7.

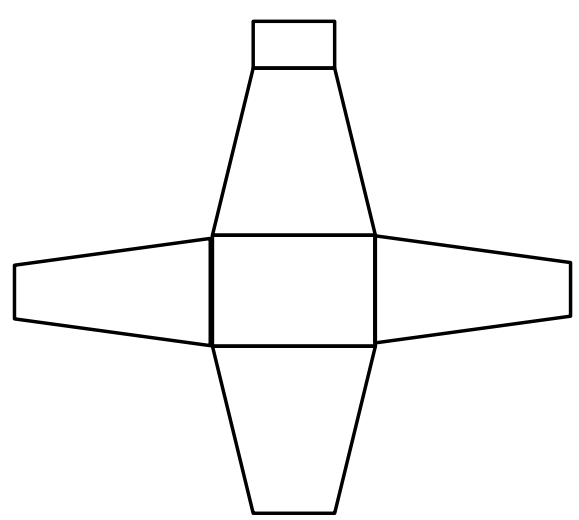

Gambar 7 Salah satu jaring-jaring hombo batu. 
DOI: https://doi.org/10.24127/ajpm.v10i1.3163

Luas permukaan adalah jumlah seluruh sisi atau bidang yang membentuk suatu bangun. Luas permukaan hombo batu adalah jumlah seluruh sisi atau bidang yang membentuk hombo batu.

Volume adalah isi atau kapasitas dari suatu bangun ruang. Volume dari hombo batu yang menyerupai limas persegi panjang terpancung adalah $V=\frac{1}{3} t\left(L_{a}+L_{b}+\sqrt{L_{a} \cdot L_{b}}\right)$ dengan $\mathrm{t}=$ tinggi limas terpancung, $L_{a}=$ luas alas dan $L_{b}=$ luas bidang.

Kesebangunan adalah konsep yang terdapat pada bidang geometri. Pada kesebangunan dikenal 2 hal yaitu sebangun dan kongruen. Dua bangun dikatakan sebangun jika memiliki sudut yang bersesuaian sama besar dan sisisisi yang bersesuaian sebanding. Sedangkan dua bangun dikatakan kongruen jika memiliki sudut yang bersesuaian sama besar dan sisi-sisi yang bersesuain sama panjang. Pada hombo batu kedua hal ini tentu melekat pada sisi-sisinya, dimana jika sisisisinya berbentuk trapesium sama kaki maka hombo batu memiliki 3 pasang sisi yang sebangun dan 2 pasang bidang sisi yang kongruen. Sebaliknya jika sisinya berbentuk trapesium sembarang maka hombo batu memiliki 2 pasang sisi yang sebangun dan 1 pasang sisi yang kongruen.

Refleksi adalah suatu transformasi pada bidang geometri dengan tidak mengubah ukutan atau bentuk dari bangun yang hendak direfleksikan. Pada hombo batu yang memiliki sisi berbentuk trapesium sama kaki maka terdapat 2 pasang sisi hasil refleksi terhadap sumbu simetrinya. Sebaliknya, jika sisinya berbentuk trapesium sembarang maka hombo batu memiliki 1 pasang sisi hasil refleksi terhadap sumbu simetrinya.
Dilatasi adalah suatu transformasi pada bidang geometri dengan mengubah ukuran (memperbesar atau memperkecil) namun tidak merubah bentuk bangun tersebut. Pada hombo batu konsep dilatasi dapat dilihat dari hubungan antara sisi bawah dengan sisi atas.

Pola bilangan yang merupakan susunan bilangan tertentu yan memiliki aturan yang tetap pada setiap sukunya. Hal ini pun berhubungan dengan media hombo batu yang disusun berdasarkan pola dan aturan tertentu. Seperti yang diketahui pada media hombo batu yang disusun dari batu-batu, dimana jumlah batu pada susunan pertama, lebih banyak pada susunan kedua, jumlah batu pada susunan kedua lebih banyak pada susunan berikutnya, dan seterusnya. Hal ini mengikuti aturan dari pada pola bilangan yang memiliki pola dan aturan tertentu. Untuk lebih jelas, dapat dilihat pada Gambar 8.

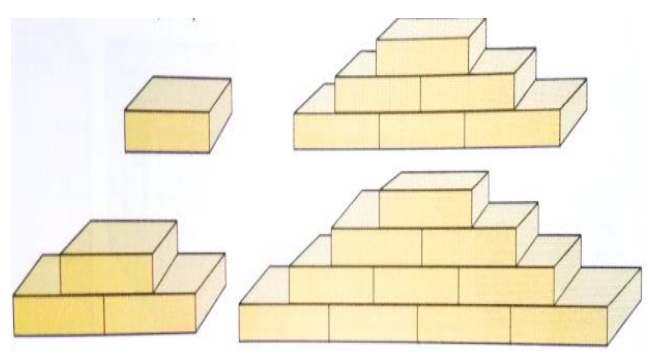

Gambar 8. Susunan batu pada hombo batu

Susunan batu pada Gambar 8 memenuhi aturan pola bilangan yaitu $\frac{n(n+1)}{2}$. Sehingga melalui media hombo batu ini akan membantu siswa untuk mengantarkan pemahaman mereka dalam mempelajari tentang pola bilangan diantaranya tentang barisan dan deret.

Kosep-konsep matematika yang diperoleh dari hasil identifikasi hombo batu tersebut disimpulkan dan disajikan pada Tabel 1. 
DOI: https://doi.org/10.24127/ajpm.v10i1.3163

Tabel 1. Konsep-konsep matematika pada hombo batu

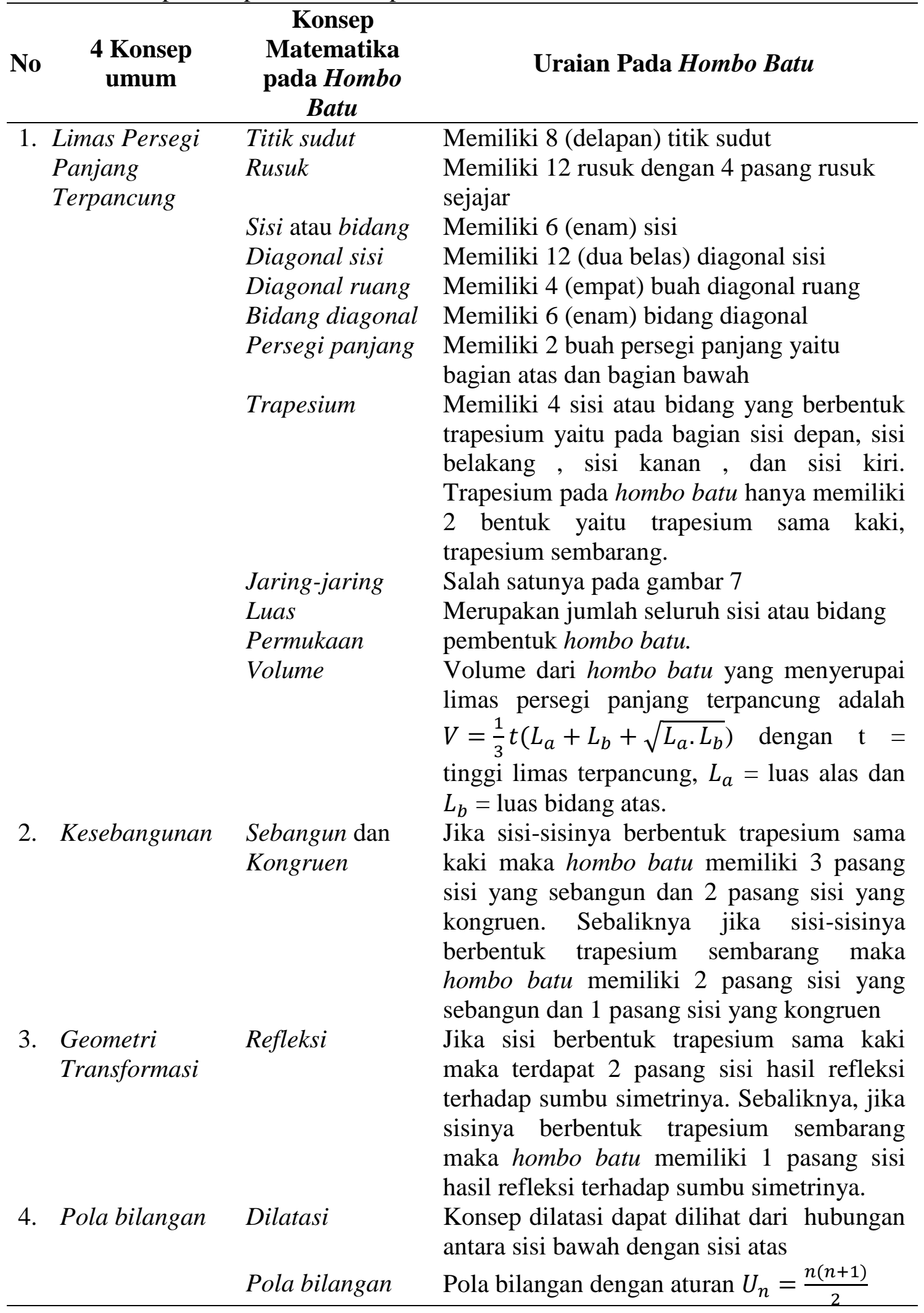


Berdasarkan Tabel 1 dapat disimpulkan bahwa budaya hombo batu berisi konsep-konsep matematika. Secara umum ada 4 konsep matematika di dalam hombo batu yaitu limas persegi panjang terpancung, kesebangunan, geometri transformasi, dan pola bilangan. Konsep-konsep matematika ini ditinjau dari bentuk dan susunan batu hombo batu. Penelitian ini sejalan dengan penelitian sebelumnya yang menegaskan bahwa hombo batu mengandung konsep gerak parabola pada bidang fisika yang identik dengan konsep persamaan kuadrat pada bidang matematika (Gea, 2017). Penelitian tersebut ditinjau berdasarkan pengertian bahwa hombo batu sebagai loncat batu, namun penelitian ini ditinjau berdasarkan karakteristik bentuk dari hombo batu. Hal ini semakin membuktikan bahwa budaya hombo batu tidak hanya digunakan sebagai budaya dalam melatih fisik pemuda Nias atau memiliki nilai karakter (Siregar \& Syamsuddin, 2015) namun juga budaya ini dapat digunakan dalam proses pembelajaran (Gea, 2017; Kamid et al., 2020) khususnya matematika. Pembelajaran matematika yang diintegrasikan dengan budaya dikenal dengan istilah etnomatematika dimana siswa dapat belajar tentang budaya, belajar budaya, dan belajar melalui budaya (Supriadi et al., 2016) melalui pembelajaran kontekstual (Pratikno, 2018) dan matematika realistik (Gee, 2019).

Pembelajaran matematika dengan konteks hombo batu mengarahkan siswa untuk belajar matematika berbasis budaya hombo batu. Dalam hal ini hombo batu dijadikan sebagai media pembelajaran. Melalui media pembelajaran hombo batu ini siswa mampu memahami (Sarumaha, R., Harefa, D., \& Zagoto, 2018) dengan mudah konsep-konsep matematika yang sifatnya abstrak. Melalui media pembelajaran hombo batu siswa dapat memahami bahwa matematika itu sangat dekat dengan keseharian (Fajriyah, 2018; Herlina \& Hartono, 2015) mereka dan semakin yakin bahwa matematika itu dapat dipelajari melalui budaya sendiri. Dengan demikian dapat dikatakan bahwa budaya hombo batu di Nias Selatan merupakan bagian dari ethnomathematics dan layak untuk dijadikan sebagai media pembelajaran matematika.

Pengembangan pembelajaran matematika berbasis budaya lokal (Prihastari, 2015) merupakan tugas guru mata pelajaran di sekolah. Pengembangan pembelajaran matematika dengan konteks budaya lokal (Kamid et al., 2020; Supriadi et al., 2016) dapat menciptakan nuansa pembelajaran yang mampu memberikan respon positif siswa terhadap pembelajaran matematika (Sarumaha, 2018).

Penelitian terdahulu menegaskan bahwa hombo batu sebagai media pendidikan karakter (Siregar \& Syamsuddin, 2015) dan media pembelajaran sains pada pokok bahasan gerak parabola (Gea, 2017) menjadi dasar bahwa hombo batu dapat dijadikan media pembelajaran matematika. Dengan demikian, hasil penelitian ini berimplikasi pada upaya guru dalam mengembangkan bahan ajar, alat evaluasi dan desain pembelajaran matematika berbasis budaya Nias dengan memperhatikan konsep-konsep matematika yang terkandung di dalamnya.

\section{KESIMPULAN DAN SARAN}

Berdasarkan hasil penelitian diperoleh hasil bahwa hombo batu di Kabupaten Nias Selatan tidak hanya 
memiliki nilai seni, melainkan juga bertujuan untuk melatih kekuatan fisik, ketangkasan dan semangat juang pemuda Nias. Akan tetapi, jika dilihat dari sisi bentuk dan susunan batu yang terdapat di dalamnya maka hombo batu memiliki konsep-konsep matematika yang secara umum ada 4 yaitu limas persegi panjang terpancung masingmasing titik sudut, rusuk, sisi atau bidang, diagonal sisi, diagonal ruang, bidang diagonal, persegi panjang, trapesium, jaring-jaring, luas permukaan dan volume; kesebangunan masing-masing sebangun dan kongruen; geometri transformasi masing-masing refleksi dan dilatasi; serta pola bilangan. Disamping itu hombo batu juga dapat digunakankan sebagai media pembelajaran matematika khususnya pada materi geometri dan pola bilangan.

Pembelajaran matematika yang dihubungkan dengan budaya memicu kreativitas siswa pada proses pembelajaran dan menumbuhkan rasa cinta budaya pada diri siswa. Sehingga disarankan agar budaya Nias lainya dapat dikaji dari sudut pandang etnomatematika sehingga dapat dijadikan sebagai media pembelajaran matematika.

\section{DAFTAR PUSTAKA}

Dwidayati, N. (2019). Analisis Bangunan Temple di Kyoto Jepang dalam Perspektif Etnomatematika. PRISMA: Prosiding Seminar Nasional Matematika, 2, 46-50.

Fajriyah, E. (2018). Peran etnomatematika terkait konsep matematika dalam mendukung literasi. PRISMA: Prosiding Seminar Nasional Matematika, 1, 114-119.

https://journal.unnes.ac.id/sju/inde x.php/prisma/
Fauzi, A., \& Lu'luilmaknun, U. (2019). Etnomatematika Pada Permainan Dengklaq Sebagai Media Pembelajaran Matematika. AKSIOMA: Jurnal Program Studi Pendidikan Matematika, 8(3), 408. https://doi.org/10.24127/ajpm.v8i3 .2303

Gea, W. J. (2017). Lompat Batu Sebagai Media Pembelajaran Sains Berbasis Budaya Lokal Pada Pokok Bahasan Gerak Parabola. Universitas Sanata Dharma Yogyakarta.

Gee, E. (2019). Kemampuan Pemecahan Masalah Matematika Melalui Alur Belajar Berbasis Realistic Mathematics Education (Rme). Jurnal Education and Development, 7(3), 269.

Hariyadi, S., \& Muttaqin., M. F. (2020). Pemahaman Konsep Geometri Pada Pembelajaran Problem Based Learning Bermuatan Etnomatematika Bangunan Cagar Budaya Kota Semarang. Jurnal Review Pendidikan Dasar:Jurnal Kajian Pendidikan Dan Hasil Penelitian, 6(3).

Herlina, R., \& Hartono, Y. (2015). Etnomatematika dalam budaya rumah adat palembang. Prosiding Seminar Nasional Etnometnesia, 849-858.

Kamid, Yuliya, S., \& Muhaimin. (2020). Pengembangan Modul Panduan Guru Matematika dalam Mendesain Pembelajaran PjBJ Berbasis Budaya Jambi. AKSIOMA: Jurnal Program Studi Pendidikan Matematika, 9(2), 424-432.

https://doi.org/10.24127/ajpm.v9i2 .2796 
Laurens, T. (2017). Analisis Etnomatematika Dan

Penerapannya Dalam

Meningkatkan Kualitas

Pembelajaran. Jurnal LEMMA, 3(1), 86-96.

https://doi.org/10.22202/j1.2016.v1 i3.1120

Mustawhisin, A. N., Puji, R. P. N., \& Hartanto, W. (2019). Sejarah Kebudayaan: Hasil Budaya Material dan Non-Material Akibat Adanya Pengaruh Islam di Nusantara. SINDANG: Jurnal Pendidikan Sejarah Dan Kajian Sejarah, 1(2), 54-66.

Noto, M. S., Firmasari, S., \& Fatchurrohman, M. (2018). Etnomatematika pada sumur purbakala Desa Kaliwadas Cirebon dan kaitannya dengan pembelajaran matematika di sekolah Ethnomathematics at the sumur purbakala Kaliwadas Village of Cirebon and relationship with mathematics learning in school. Jurnal Riset Pendidikan Matematika, 5(2), 201-210.

Pratama, S., Minarni, A., \& Saragih, S. (2017). Development of learning devices based on realistic approach integrated context malay deli culture to improve ability of understand mathematical concepts and students' self-regulated learning at SMP negeri 5 medan. IOSR Journal of Mathematics, 13(6), 18-29.

Pratikno, H. (2018). Etnomatematika pada Bregada Prajurit Keraton Yogyakarta. Prosiding Seminar Nasional Etnomatnesia, 795-802.

Prihastari, E. B. (2015). Pemanfaatan Etnomatematika Melalui Permainan Engklek Sebagai Sumber Belajar. Mendidik: Jurnal Kajian Pendidikan Dan
Pengajaran, 1(2), 155-162.

Puspadewi, K. R., \& Putra, I. G. N. N. (2014). Etnomatematika di Balik Kerajinan Anyaman Bali. Jurnal Matematika, 4(2), 80-89.

Risdiyanti, I., \& Prahmana, R. C. I. (2018). Etnomatematika:

Eksplorasi dalam Permainan Tradisional Jawa. Journal of Medives: Journal of Mathematics Education IKIP Veteran Semarang, 2(1). https://doi.org/10.31331/medives.v $2 \mathrm{i} 1.562$

Sarumaha, R., Harefa, D., \& Zagoto, M. . (2018). Upaya Meningkatkan Kemampuan Pemahaman Konsep geometri Transformasi Refleksi Siswa Kelas XII-IPA-B SMA Kampus Telukdalam Melalui Model Pembelajaran Discovery learning Berbantuan Media Kertas Milimeter. Jurnal Education and Development, 6(1), 90-96.

Sarumaha, R. (2018). Upaya meningkatkan kemampuan pemahaman konsep matematis siswa smas kampus telukdalam melalui model pembelajaran penemuan terbimbing. Jurnal Education and Development, 3(1), 68-72.

Siagian, M. D. (2016). Kemampuan koneksi matematik dalam pembelajaran matematika. MES: Journal of Matematics Education and Science 2, 2(1), 58-67.

Siregar, A. Z., \& Syamsuddin. (2015). Tradisi Hombo Batu di Pulau Nias: Satu Media Pendidikan Karakter Berbasis Kearifan Lokal. South-East Asian Journal for Youth, Sport \& Health Education (Sipatahoenan), 1(October), 209218.http://journals.mindamas.com/ index.php/sipatahoenan/article/vie w/687 
DOI: https://doi.org/10.24127/ajpm.v10i1.3163

Supriadi, Arisetyawan, A., \& Tiurlina. (2016). Mengintegrasikan pembelajaran matematika berbasis budaya banten pada pendirian sd laboratorium upi kampus serang. Mimbar Sekolah Dasar, 3(1), 118.https://doi.org/10.17509/mimba r-sd.v3i1.2510

Ulya, H., \& Rahayu, R. (2020). Kemampuan Representasi Matematis Field Intermediate dalam Menyelesaikan Soal Etnomatematika. AKSIOMA: Jurnal Program Studi Pendidikan Matematika, 9(2), 451-466. 